\title{
Preliminary testing of NASA's Molecular Adsorber Coating technology for future missions to Mars
}

\author{
Nithin S. Abraham, Doris E. Jallice \\ NASA Goddard Space Flight Center, 8800 Greenbelt Road, Greenbelt, MD 20771 USA
}

\begin{abstract}
The Molecular Adsorber Coating (MAC) is a sprayable coatings technology that was developed at NASA Goddard Space Flight Center (GSFC). The coating is comprised of highly porous, zeolite materials that help capture outgassed molecular contaminants on spaceflight applications. The adsorptive capabilities of the coating can alleviate molecular contamination concerns on or near sensitive surfaces and instruments within a spacecraft. This paper will discuss the preliminary testing of NASA's MAC technology for use on future missions to Mars. The study involves evaluating the coating's molecular adsorption properties in simulated test conditions, which include the vacuum environment of space and the Martian atmosphere. MAC adsorption testing was performed using a commonly used plasticizer called dioctyl phthalate (DOP) as the test contaminant.
\end{abstract}

Keywords: molecular adsorber coating, molecular adsorbers, getters, MAC, zeolite, coatings technology, outgassing, molecular contamination, contamination control, vacuum chamber, Martian environment, Mars, CO2, carbon dioxide, dioctyl phthalate, DOP, plasticizer

\section{INTRODUCTION}

\subsection{Mars Exploration}

For many decades, NASA and its international partners have been at the forefront of Mars exploration through a series of missions, which have included orbiters and landers. Mars, the fourth planet from the Sun and often referred to as the "Red Planet", has been of particular interest to scientists due to the possibility that it may have previously supported life. Accordingly, the science goals of NASA's Mars Exploration Program (MEP) include determining the planet's potential for prior habitability and biological life, understanding the processes and history of climate on Mars, studying the geological origins and evolution of the planet, and lastly, paving the way towards human exploration in the future. Highly sensitive mobile laboratories abroad the rovers perform experiments, which include trace organic analysis of collected samples. However, cross-contamination can interfere with the scientific findings because the presence of molecular contaminants can disguise potential signs of life or show false positives. Therefore, maintaining cleanliness of the spacecraft through all the phases of the mission has become one of the most challenging aspects on upcoming Mars missions, including the Mars 2020 and the ExoMars rovers. As a result, there is a current need to explore innovative contamination control mitigation methods. ${ }^{1-7}$

\subsection{Molecular Adsorber Coatings}

An existing coatings technology developed by NASA Goddard Space Flight Center (GSFC) has the potential to mitigate molecular contamination concerns for various spaceflight applications. This technology called the Molecular Adsorber Coating (MAC) is a zeolite-based coating that was designed to passively entrap outgassed species that may otherwise deposit on critical instruments and components, and degrade the performance and lifetime of the mission. These outgassed contaminants may originate from commonly used materials on the spacecraft, such as adhesives, lubricants, epoxies, and potting compounds. ${ }^{8-14}$ 
The MAC technology has been ground tested and flight qualified at some of the representative spaceflight conditions, which include high vacuum pressures and moderate temperature ranges. To date, several NASA missions have found practical applications for this sprayable paint technology. For example, the Ionospheric Connection Explorer (ICON) installed MAC plates within its contamination sensitive Far Ultraviolet (FUV) instrument to reduce the effects of on-orbit material outgassing. The James Webb Space Telescope (JWST), among many other missions, have also extensively used the MAC technology as an effective contamination getter during vacuum chamber testing of critical flight and optical ground support hardware. ${ }^{8-14}$

\section{APPROACH}

\subsection{Test Background}

A preliminary study was performed to evaluate the molecular adsorption properties of the MAC technology in two relevant environments for future Mars exploration missions. The two exposure conditions, which include the vacuum environment of space and the Martian atmosphere, were tested in two phases as described in Table 1.

\begin{tabular}{|c|c|c|c|}
\hline Phase ID & Simulated Environment & Test Pressure Range & Gas Purge \\
\hline A & Vacuum of Space & High Vacuum $\left(10^{-7}\right.$ Torr $)$ & - \\
\hline B & Mars Atmosphere & Low Vacuum (7 Torr) & Carbon Dioxide \\
\hline
\end{tabular}

Table 1. Summary of Test Exposure Conditions

\section{Phase A: Space Environment}

Phase A of the study involved testing under high vacuum conditions to simulate the voyage of the spacecraft in space to Mars. This cruise period can typically vary depending on the launch conditions, such as the orbit between Earth and Mars, as well as, the propulsion technology that is available. ${ }^{15-16}$ However, the average journey to Mars from Earth is about 9 months. ${ }^{15-16}$ As shown in Table 1, the testing pressure range for Phase A is $10^{-7}$ Torr, which is achievable using a test vacuum chamber.

\section{Phase B: Mars Environment}

In comparison, Phase B of the study involved testing under low vacuum conditions with carbon dioxide to simulate the contact of the spacecraft in the Martian atmosphere. The atmospheric pressure on the surface of Mars can vary from about 3 to 7 Torr depending on seasonal variations. ${ }^{17}$ As shown in Table 1, the testing pressure range for Phase B is 7 Torr. Furthermore, the Martian atmosphere is comprised of about 96 percent carbon dioxide with trace levels of argon, nitrogen, and oxygen. ${ }^{4,15}$ As a result, a gas purge with carbon dioxide was also implemented during Phase B testing.

\subsection{Sample Fabrication}

For this study, NASA GSFC fabricated a total of 26 aluminum foil samples. Two batches of the samples were coated with the white version of the MAC technology called MAC-W. A summary of the sample batches is shown in Table 2. The first batch has an average coating thickness of $0.18 \mathrm{~mm}$, or 7.2 mils. The second batch has an average coating thickness of $0.13 \mathrm{~mm}$, or 5.3 mils. The coating area per sample was approximately $3.9 \mathrm{~cm}^{2}$. 


\begin{tabular}{|c|c|c|c|}
\hline Batch ID & Number of Samples & MAC Type & Average Coating Thickness \\
\hline I & 13 & MAC-W & 7.2 mils \pm 1.0 \\
\hline II & 13 & MAC-W & 5.3 mils \pm 1.0 \\
\hline
\end{tabular}

Table 2. Summary of MAC Sample Batches

\subsection{Sample Conditioning}

During the Assembly, Test, and Launch Operations (ATLO) phases of a NASA Mars mission, the flight hardware will be exposed to a relative humidity (RH) and temperature controlled environment until launch. Similarly, the MAC samples were conditioned prior to testing in a RH and temperature controlled laboratory for a duration of approximately 45 days. The average $\mathrm{RH}$ and temperature of the room were 52 percent and $23^{\circ} \mathrm{C}$, respectively. The purpose of the conditioning period is twofold. First, the sample conditioning simulates the expected exposure of the spacecraft components to ATLO conditions. This exposure will also evaluate any impact of moisture and trace levels of ambient offgassed species in the room to the adsorption capabilities of the coating while not in use.

\subsection{Test Configuration}

Previous experiments have studied the molecular adsorption properties of MAC. ${ }^{8-14}$ These tests were executed by saturating the coating with a known contaminant source at a specified temperature within the confines of a test apparatus in a vacuum chamber. ${ }^{8-14} \mathrm{~A}$ similar test configuration is used to perform this two phase preliminary study. The samples were placed in two trays in the upper compartment of the test apparatus. As shown in Figure 1, this upper compartment consists of a top sample tray and a bottom sample tray. A contaminant source was placed at the base of the test apparatus in the lower compartment as demonstrated in Figure 1. The test apparatus, which has a total volume of $0.021 \mathrm{~m}^{3}$, was installed in a bell jar shaped vacuum chamber, which has a total volume of $0.24 \mathrm{~m}^{3}$.

A Quartz Crystal Microbalance (QCM) was positioned on a plate that was connected to another cold plate. The QCM was used to detect the flux of contaminants that escape the apparatus during the test. The QCM rates provide a good indication for when the samples reach saturation, or approach its molecular adsorption capacity. Molecular adsorption capacity, also referred to as molecular capacitance, is defined as the measure of the coating's capability to adsorb or entrap outgassed materials, or molecular contaminants. Previous studies have shown that the molecular adsorption capacity of MAC is dependent on various parameters, such as the coating thickness, the surface area coverage, the type of contaminants, the duration of exposure to the contaminant, and other test conditions. ${ }^{8-14}$

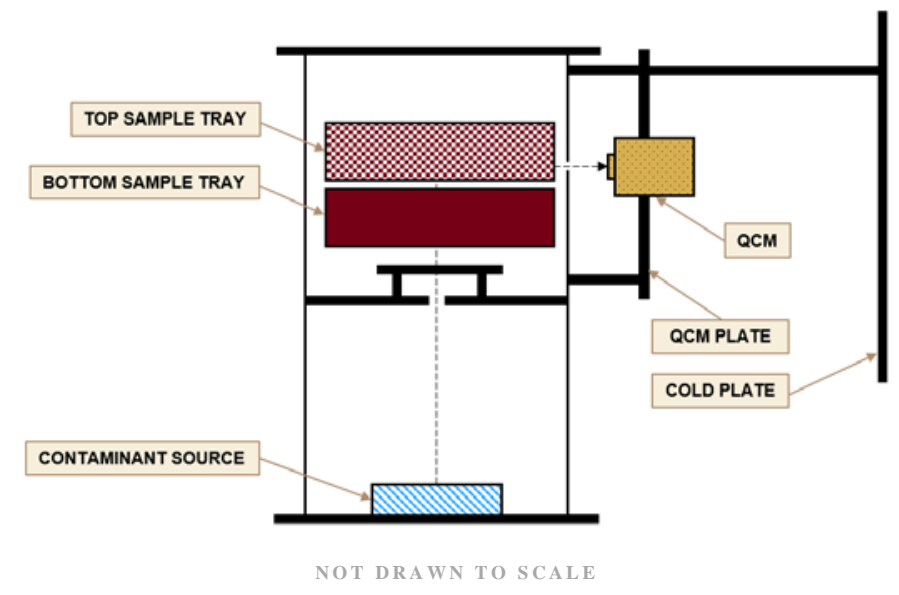

Figure 1. Design of Test Apparatus for Molecular Adsorption Testing 


\subsection{Contaminant Source}

In spaceflight applications, the presence of outgassed species, such as hydrocarbons, silicones, and plasticizers, can cause performance degradation in instruments and other critical components on the spacecraft. Previous experiments have studied the molecular adsorption capacity of the MAC technology using a volatile, long-chain hydrocarbon species called stearyl alcohol, and a complex, silicone-based compound called DC-704 diffusion pump oil. ${ }^{8-14}$ Consequently, the contaminant source that was selected for this preliminary study was a plasticizer.

A common plasticizer that is found in scavenger plate and cold finger rinses of vacuum chambers where spacecraft components are tested is dioctyl phthalate, or DOP. DOP is a single component, high molecular weight plasticizer that is an ester of phthalic acid. It is commonly found in polymers, resins, elastomers, cosmetics, and pesticides. DOP has a chemical formula of $\mathrm{C}_{24} \mathrm{H}_{38} \mathrm{O}_{4}$ and a molecular weight of $390.56 \mathrm{~g} / \mathrm{mol}$. Its appearance is described as a colorless, odorless, oily non-volatile liquid. Other synonyms for the selected contaminant source include bis(2ethylhexyl) phthalate, DEHP, diethylhexyl phthalate, or phthalic acid bis(2-ethylhexyl ester). For this study, DOP with a purity of $\geq 99.5$ percent was purchased from Sigma Aldrich. ${ }^{18-19,21}$

\subsection{Test Run Summary}

The test is divided into three parts as illustrated in Figure 2. The first part of the test flow consists of a chamber background run. The purpose of this initial run is to perform a vacuum bake-out of the test apparatus at various temperatures and to establish the final background conditions of the vacuum chamber prior to testing. As shown in Table 3, no contaminant source or MAC samples were placed in the test apparatus during the chamber background run.

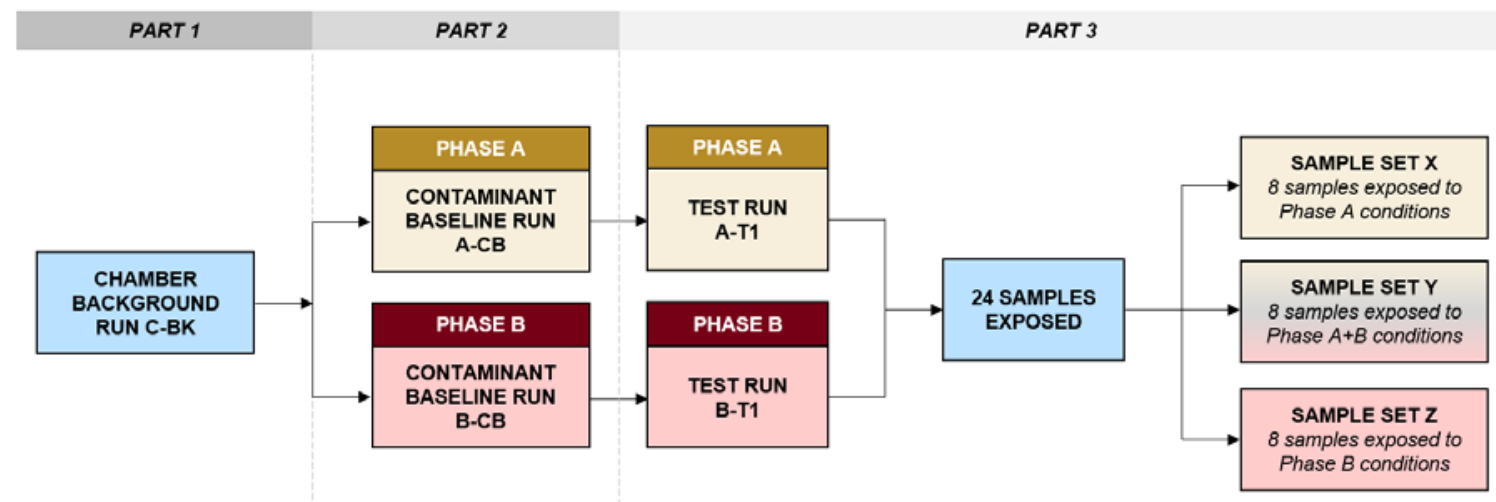

Figure 2. Summary of Test Run Flow per Part

\begin{tabular}{|c|c|c|c|c|c|c|}
\hline $\begin{array}{c}\text { Part } \\
\#\end{array}$ & Run ID & $\begin{array}{c}\text { Phase } \\
\text { A }\end{array}$ & $\begin{array}{c}\text { Phase } \\
\text { B }\end{array}$ & $\begin{array}{c}\text { Test } \\
\text { Apparatus }\end{array}$ & $\begin{array}{c}\text { Contaminant } \\
\text { Source }\end{array}$ & $\begin{array}{c}\text { MAC } \\
\text { Samples }\end{array}$ \\
\hline 1 & Chamber Background & $\mathrm{X}$ & & $\mathrm{X}$ & & \\
\hline 2 & Contaminant Baseline & $\mathrm{X}$ & $\mathrm{X}$ & $\mathrm{X}$ & $\mathrm{X}$ & \\
\hline 3 & Sample Test & $\mathrm{X}$ & $\mathrm{X}$ & $\mathrm{X}$ & $\mathrm{X}$ & $\mathrm{X}$ \\
\hline
\end{tabular}

Table 3. Summary of Test Components per Part 
The second part of the test flow consists of two contaminant baseline runs, where the contaminant source was exposed to Phase A and Phase B conditions. The purpose of these runs is to establish the stabilization rate of the contaminant source at various temperatures and in the absence of any MAC samples. The best temperature to heat the contaminant source to during the two different phases was also determined.

The last part of the test flow consists of the sample test runs, where the MAC samples were exposed to the contaminant source at Phase A and Phase B conditions. A total of 24 samples, which were divided into three sample sets, were contaminated during the test runs. As displayed in Figure 2, Sample Set X includes 8 of the 24 samples that were exposed to Phase A conditions only. Sample Set $\mathrm{Y}$ consists of another eight samples that were exposed to both phase conditions. Lastly, Sample Set Z contains the remaining eight samples that were exposed to Phase B conditions only.

\subsection{Chamber Background Run}

Part 1. Run C-BK

The chamber background run was performed for approximately 125 hours. The test apparatus was baked out at various temperatures, which included 25,45 , and $70^{\circ} \mathrm{C}$. The vacuum chamber was operating at a pressure of $2.0 \mathrm{x}$ $10^{-7}$ Torr. With the cold plate at $-170^{\circ} \mathrm{C}$, the QCM was set to $-60^{\circ} \mathrm{C}$ and was used to determine the response rates of the chamber background. After the bake-out, the lowest stabilization rate that was achieved from the chamber background was $25 \mathrm{~Hz} / \mathrm{hr}$.

\subsection{Contaminant Baseline Runs}

\section{Part 2. Run A-CB}

Next, the contaminant baseline run at Phase A conditions was performed for approximately 65 hours. About $2.5 \mathrm{~g}$ of DOP was poured into an aluminum dish and placed at the base of the test apparatus as shown in Figure 1. No MAC samples were placed in the test apparatus for this run. The same cold plate and QCM temperature parameters from the chamber background were also implemented. However, this time the QCM was used to determine the response rates of the contaminant source at a specified temperature. A source temperature of $60{ }^{\circ} \mathrm{C}$ was selected because it provides an accelerated rate of the material in Phase A conditions, but also results in the minimal maintenance of the QCM throughout the length of the test. As illustrated in Figure 3, the QCM rate stabilized at around $840 \mathrm{~Hz} / \mathrm{hr}$ with the test apparatus and contaminant source at $60^{\circ} \mathrm{C}$ and the chamber pressure at $2.4 \times 10^{-7}$ Torr.

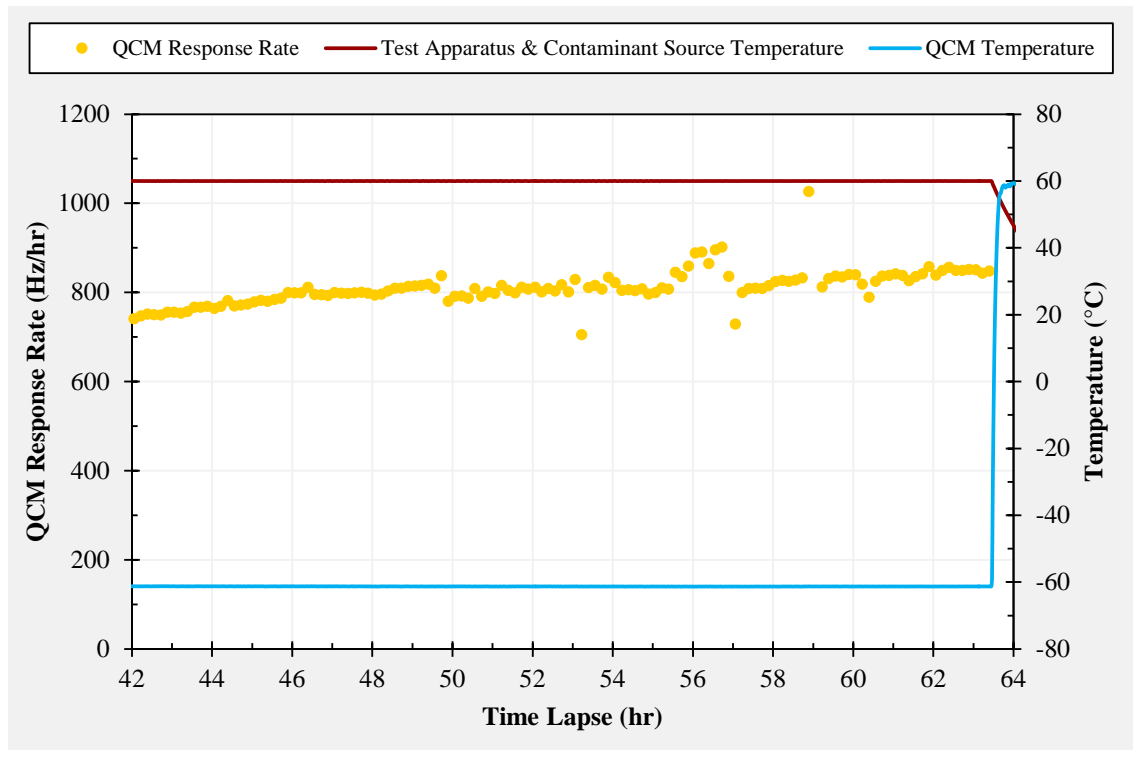

Figure 3. QCM Response Rate and Temperature Profile for Phase A Contaminant Baseline Run 


\section{Part 2. Run B-CB}

Similarly, a contaminant baseline run was also completed at Phase B conditions. First, the chamber was pumped down to rough vacuum. Following this, the pump valve was partially closed and throttled while purging carbon dioxide into the chamber. The chamber was then isolated when a steady pressure of 7 Torr was achieved. Unfortunately, the same temperature parameters that were applied during Phase A could not be achieved for the Phase B contaminant baseline run because of the many challenges that were experienced. The first challenge was the occurrence of snow and ice build-up on the cold surfaces of the test components. It was assumed that this was due to the presence of carbon dioxide in the system, which condensed on the cold surfaces. As a result, the QCM and cold plate temperature parameters were changed to 25 and $0{ }^{\circ} \mathrm{C}$, respectively.

The second challenge was that it was difficult to reach and maintain temperatures of at least $60{ }^{\circ} \mathrm{C}$. It was assumed that this was likely attributed to the dominating convective heat transfer forces, as well as, some limitations with the heater power on the apparatus. The most achievable test apparatus and contaminant source temperature at these conditions was $45^{\circ} \mathrm{C}$; thus, this temperature was used for the Phase B sample test run. However, it was observed that the QCM detected little to no deposition of the contaminant source or the chamber background. This may be attributed to DOP not reaching its equilibrium vapor pressure. The vapor pressure of DOP at $45{ }^{\circ} \mathrm{C}$ was estimated at approximately $2.2 \times 10^{-6}$ Torr. This specific value was calculated using the Clausius-Clapeyron equation, where the gas constant is $8.3145 \mathrm{~J} / \mathrm{mol}-\mathrm{K}$, the enthalpy of vaporization based on Perry and Weber data at $125{ }^{\circ} \mathrm{C}$ is 107.6 $\mathrm{kJ} / \mathrm{mol}$, and the vapor pressure of DOP at $25{ }^{\circ} \mathrm{C}$ per the Hazardous Substances Data Bank (HSDB) is $1.42 \times 10^{-7}$ mmHg. ${ }^{19-22}$ Therefore, since vapor pressure is a good indication of a liquid's evaporation rate, it is assumed that the contaminant source may not easily evaporate at Phase B conditions.

\subsection{Sample Test Runs}

\section{Part 3. Run A-T1}

The sample test run at Phase A conditions was performed for approximately 100 hours and the test parameters are listed in Table 4. The contaminant source from the baseline runs was replenished to avoid depletion during the sample test runs. About $3.1 \mathrm{~g}$ of the contaminant source was placed at the base of the test apparatus. A total of 16 MAC samples were positioned on the trays in the upper compartment. Eight samples of Sample Set $X$ were placed on the bottom tray, and another eight samples of Sample Set Y were placed on the top tray as illustrated in Figure 1.

\begin{tabular}{|c|c|c|c|c|c|}
\hline $\begin{array}{c}\text { Apparatus } \\
\text { Temperature }\end{array}$ & $\begin{array}{c}\text { Contaminant } \\
\text { Temperature }\end{array}$ & $\begin{array}{c}\text { QCM } \\
\text { Temperature }\end{array}$ & $\begin{array}{c}\text { Cold Plate } \\
\text { Temperature }\end{array}$ & $\begin{array}{c}\text { Chamber } \\
\text { Pressure }\end{array}$ & $\begin{array}{c}\text { Sample } \\
\text { Set (\#) }\end{array}$ \\
\hline $60^{\circ} \mathrm{C}$ & $60^{\circ} \mathrm{C}$ & $-60^{\circ} \mathrm{C}$ & $-170^{\circ} \mathrm{C}$ & $2.0 \times 10^{-7} \mathrm{Torr}$ & $\mathrm{X}(8), \mathrm{Y}(8)$ \\
\hline
\end{tabular}

Table 4. Test Parameters for Phase A Sample Test Run

As depicted in Figure 4, the QCM response rate initially dropped from about 650 to $300 \mathrm{~Hz} / \mathrm{hr}$ within the first 20 hours of the test run. This plunge is attributed to the entrapment of outgassed DOP onto the pores of the coating. Over the next 60 hours, the QCM rate is observed to gradually increase towards its baseline parameters. This increase is due to the surface adsorption sites on the coating filling up, or reaching its saturation with DOP. Thus, more of the contaminant species are exiting the test apparatus and depositing onto the QCM. Finally, the QCM rate appeared to level off between 870 and $940 \mathrm{~Hz} / \mathrm{hr}$. Recall that the Phase A contaminant baseline run stabilized at around $840 \mathrm{~Hz} / \mathrm{hr}$ as shown in Figure 3. The increased shift from this baseline may be due to excessive DOP buildup on the QCM crystal. Note that a QCM cleaning was attempted at a time lapse of 240 hours as shown by the increase in the QCM temperature in Figure 4. 


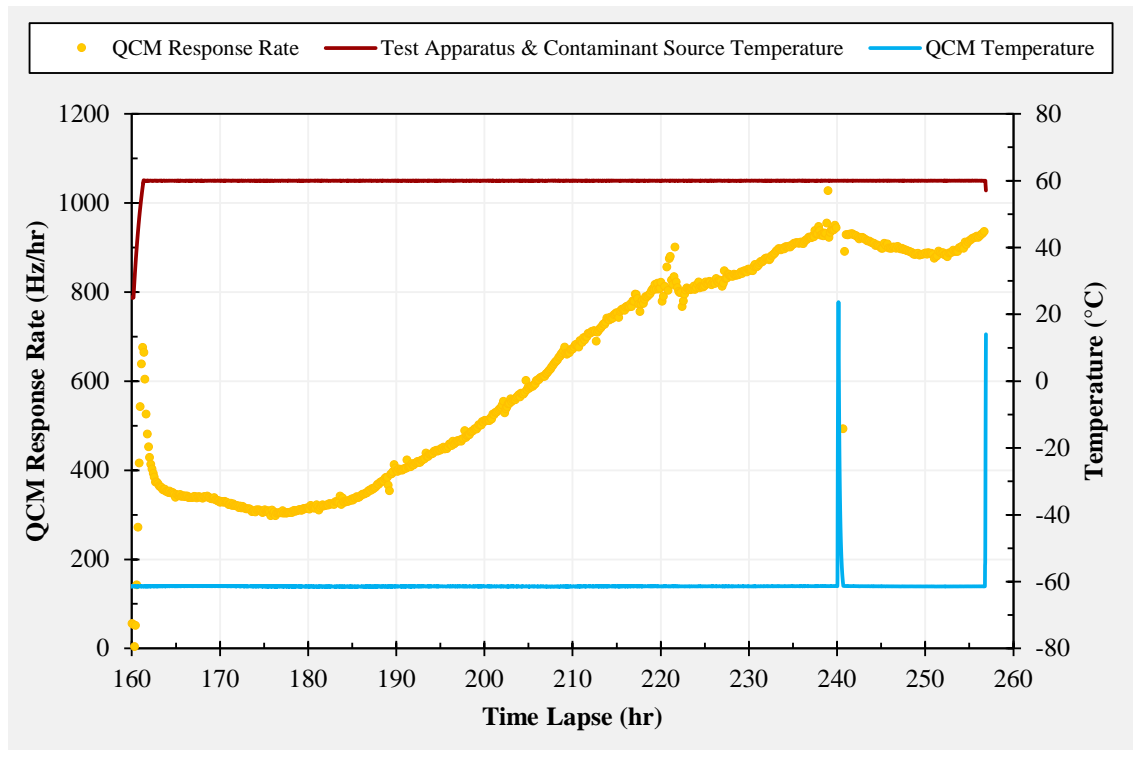

Figure 4. QCM Response Rate and Temperature Profile for Phase A Sample Test Run

Part 3. Run B-T1

The sample test run at Phase B conditions was performed for approximately 140 hours and the test parameters are summarized in Table 5. The eight contaminated samples of Sample Set X were removed from the test apparatus, and replaced with eight unexposed, conditioned samples of Sample Set Z. The eight samples of Sample Set Y remained in the top tray of the upper compartment.

\begin{tabular}{|c|c|c|c|c|c|}
\hline $\begin{array}{c}\text { Apparatus } \\
\text { Temperature }\end{array}$ & $\begin{array}{c}\text { Contaminant } \\
\text { Temperature }\end{array}$ & $\begin{array}{c}\text { QCM } \\
\text { Temperature }\end{array}$ & $\begin{array}{c}\text { Cold Plate } \\
\text { Temperature }\end{array}$ & $\begin{array}{c}\text { Chamber } \\
\text { Pressure }\end{array}$ & $\begin{array}{c}\text { Sample } \\
\text { Set (\#) }\end{array}$ \\
\hline $45^{\circ} \mathrm{C}$ & $45^{\circ} \mathrm{C}$ & $25^{\circ} \mathrm{C}$ & $0^{\circ} \mathrm{C}$ & 7 Torr & $\mathrm{Z}(8), \mathrm{Y}(8)$ \\
\hline
\end{tabular}

Table 5. Test Parameters for Phase B Sample Test Run

As illustrated in Figure 5, the QCM detected little to no deposition of the contaminant source or the chamber background species. The less than $1 \mathrm{~Hz} / \mathrm{hr}$ rates that are shown in Figure 5 are likely invalid readings. This made it challenging to determine when the samples will become saturated with DOP, if even possible. Therefore, the test was concluded with an additional 40 hours more than the Phase A test run. The samples were removed after the test and submitted for analysis. Additionally, the contaminant source from the Phase A and Phase B sample test runs experienced a mass loss of $0.74 \mathrm{~g}$ as shown in Table 6.

\begin{tabular}{|c|c|c|}
\hline Measurement Period & Contaminant Mass & Mass Loss \\
\hline Pre-Phase A & $3.08 \mathrm{~g}$ & \multirow{2}{*}{$0.74 \mathrm{~g}$} \\
\hline Post-Phase B & $2.34 \mathrm{~g}$ & \\
\hline
\end{tabular}

Table 6. Contaminant Mass Measurements for Sample Test Runs 


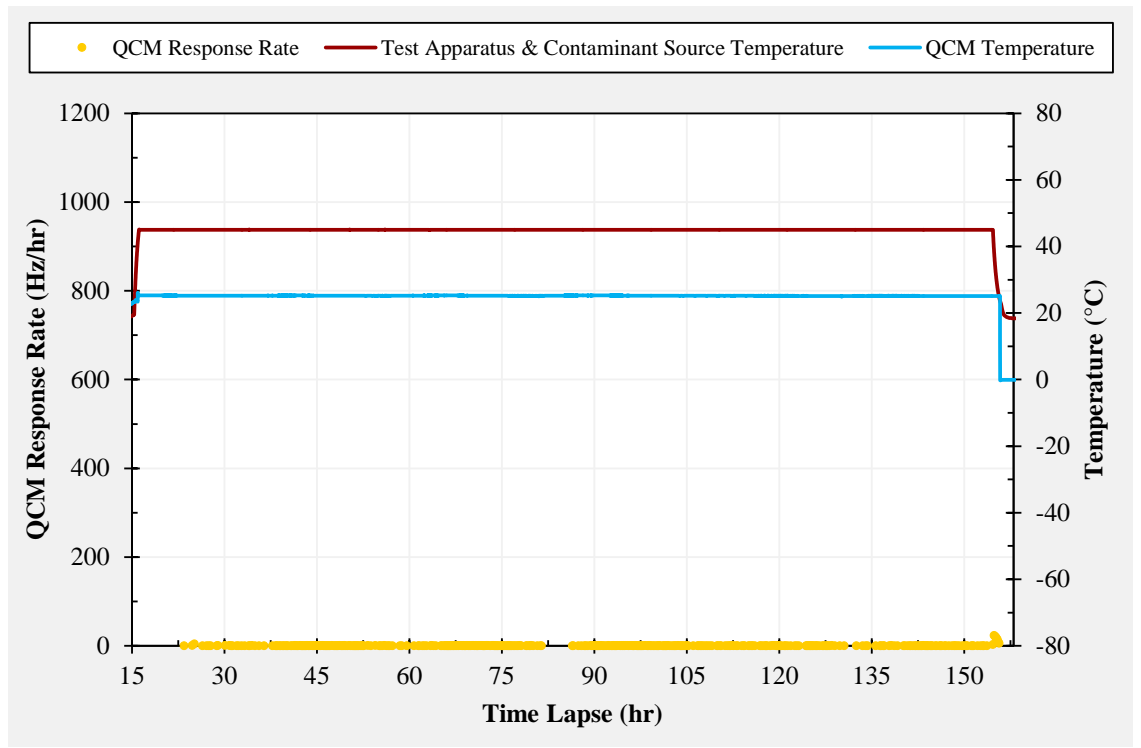

Figure 5. QCM Response Rate and Temperature Profile for Phase B Sample Test Run

\section{TEST METHODS}

\subsection{Test Analysis Summary}

A summary of the test analysis flow is illustrated in Figure 6. The test methods include gravimetric analysis on all of the contaminated samples, and chemical analysis on six of the contaminated samples and an additional two control samples, which were exposed to simulated ATLO conditions.

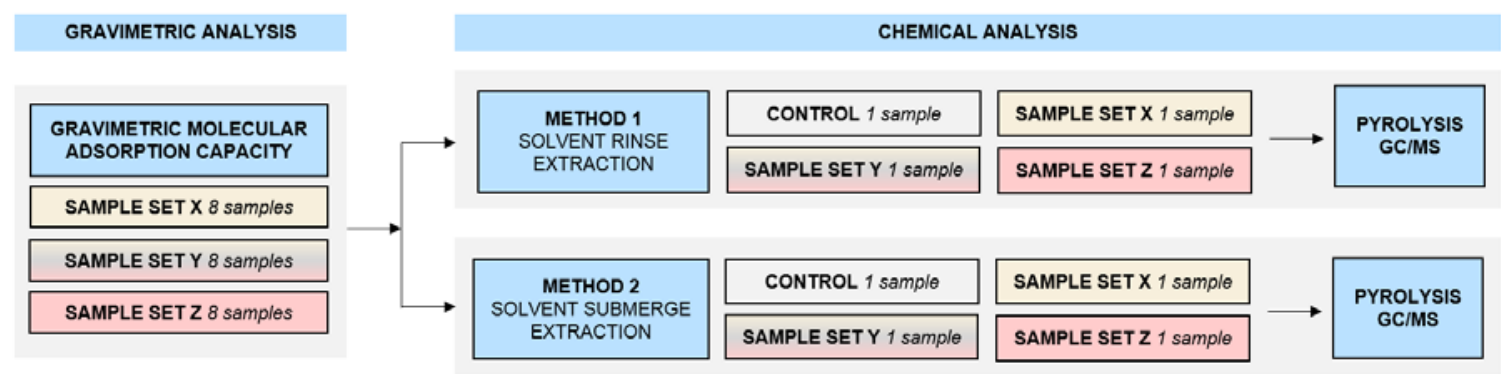

Figure 6. Summary of Gravimetric and Chemical Analysis Test Flow

\subsection{Gravimetric Analysis Method}

First, the molecular adsorption capacity of MAC was calculated based on mass changes in the coating that are attributed to the entrapment of the outgassed contaminant species during the two test phases. The gravimetric measurements, including pre-exposure and post-exposure of the samples, were performed in a nitrogen purged dry glove box with operating conditions at $25^{\circ} \mathrm{C}$ and a $\mathrm{RH}$ of less than 5 percent. Similar to previous experiments, the samples were exposed to vacuum for 48 to 72 hours prior to performing mass measurements, and a water absorption correction factor was incorporated into the calculated value to account for any errors associated with moisture in the coating. ${ }^{8}$ The gravimetric based molecular adsorption capacity was estimated for all 24 of the contaminated samples, which includes eight samples per sample set that were exposed during the two phases. 


\subsection{Chemical Analysis Methods}

As depicted in Figure 6, chemical analysis was performed on 6 of the 24 contaminated samples, as well as, two control samples using two solvent extraction methods. Method 1 is the solvent rinse method. In this first method, the surface of the coating is rinsed with chloroform three times. Method 2 is the solvent submerge method. In this second method, the sample is submerged in chloroform for approximately 30 minutes over low heat on a heater plate. The purpose of both methods is to extract and verify the DOP entrapped in the coating, as well as, compare the test results to the calculated gravimetric molecular adsorption capacity. These methods will also extract other adsorbed chemical species, but only those that can be dissolved with chloroform. Furthermore, based on previous studies, the solvent extraction methods are not expected to remove all of the adsorbed contaminants from the coating. ${ }^{13-14}$

For the two methods, the rinsates from the samples were collected and allowed to evaporate to dryness in separate pre-weighed dishes. The remaining material called the Non-Volatile Residue (NVR) was weighed and analyzed qualitatively to provide a general estimation of the relative amounts and types of chemical species in the NVR. For analysis, pyrolysis-Gas Chromatography/Mass Spectrometry (GC/MS) was performed on the NVR from both solvent extraction methods using a Shimadzu Scientific Instruments QP2010 Ultra and GL Sciences Optic-4 Inlet instrument. During pyrolysis, the NVR from each method was placed in a micro-vial inside a liner and heated in the

GC outlet. The volatile and semi-volatile chemical species were then introduced to the GC column interface with the MS. Any non-volatile chemical species remained in the micro-vial to avoid inlet contamination of the instrument.

\section{RESULTS \& DISCUSSION}

\subsection{Gravimetric Analysis Results}

The molecular adsorption capacity based on gravimetric measurements for the 24 samples that were contaminated during the test runs is illustrated in the three plots shown in Figure 7. The first plot shows the results for Sample Set $\mathrm{X}$, which was exposed to Phase A conditions for approximately 100 hours. One outlier from this sample set was omitted from the results. As shown in Figure 8, the average molecular adsorption capacity for Batch I samples was $3.22 \mathrm{mg} / \mathrm{cm}^{2}$. The average for Batch II was about 1.2 times less due to its slightly thinner coating thickness at 5.3 mils. The second plot in Figure 7 shows the results for Sample Set Y, which was exposed to Phase A for 100 hours and Phase B for 140 hours. The average molecular adsorption capacity for Batch I and Batch II samples during this exposure did not significantly differ from those samples exposed only to Phase A. The difference was within 0.1 $\mathrm{mg} / \mathrm{cm}^{2}$ as depicted in Figure 8. This observation suggests that Sample Set Y did not entrap significant amounts of DOP during Phase B.

The last plot in Figure 7 shows the results for Sample Set Z, which was exposed to Phase B conditions for 140 hours. The average molecular adsorption capacity for Batch I and Batch II were 0.85 and $0.60 \mathrm{mg} / \mathrm{cm}^{2}$, respectively. On average, when compared to Sample Sets X and Y, the results for the Phase B exposure only samples were significantly lower by a factor of 4 . This low adsorption suggests that it was unlikely that the coating approached saturation with the contaminant source during this last phase of testing. Additionally, it can be assumed that there was limited outgassing of the source material in the low vacuum conditions of Phase B. In this case, the DOP source most likely did not reach its vapor pressure at Phase B conditions. Regardless, some limited adsorption did occur within the allocated time frame of the test, possibly originating from the lingering DOP species that existed in the test apparatus from the previous Phase A exposure. 

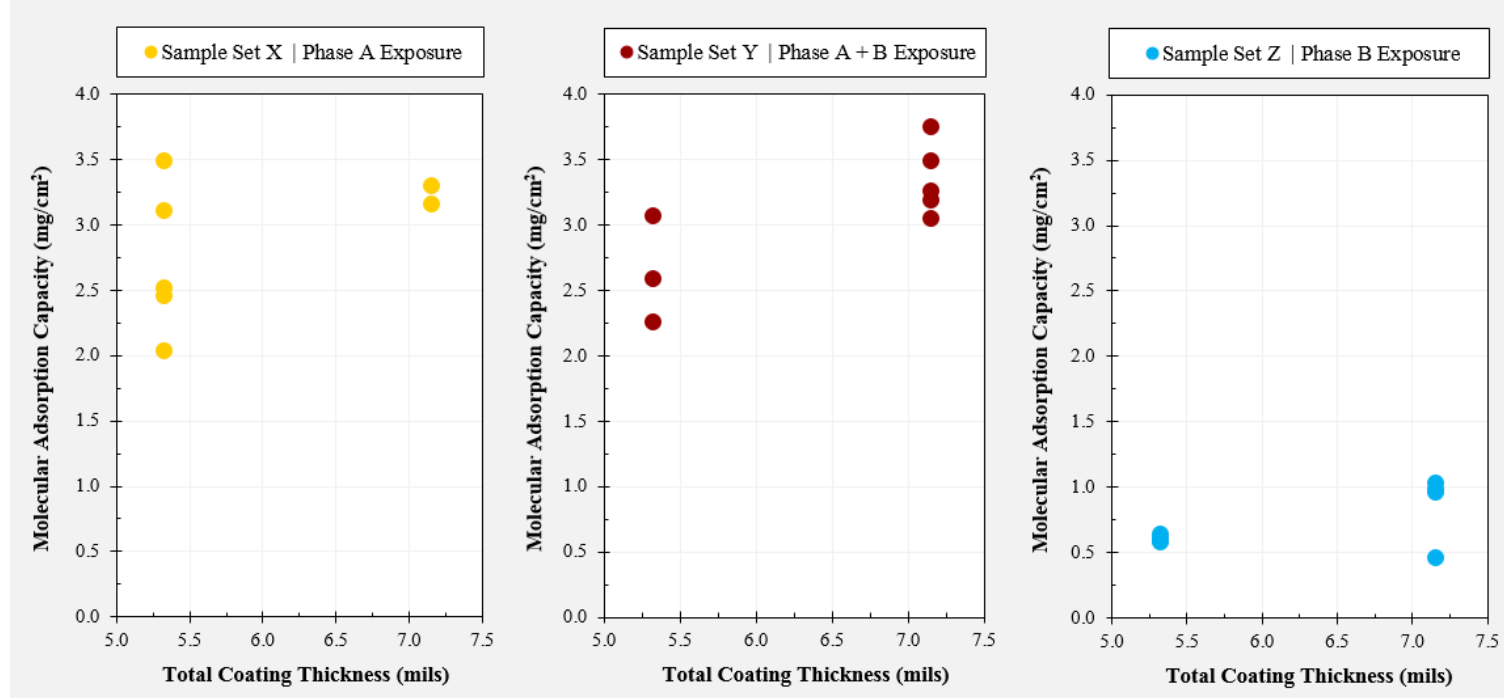

Figure 7. Gravimetric Molecular Adsorption Capacity per Sample Set and Phase Conditions

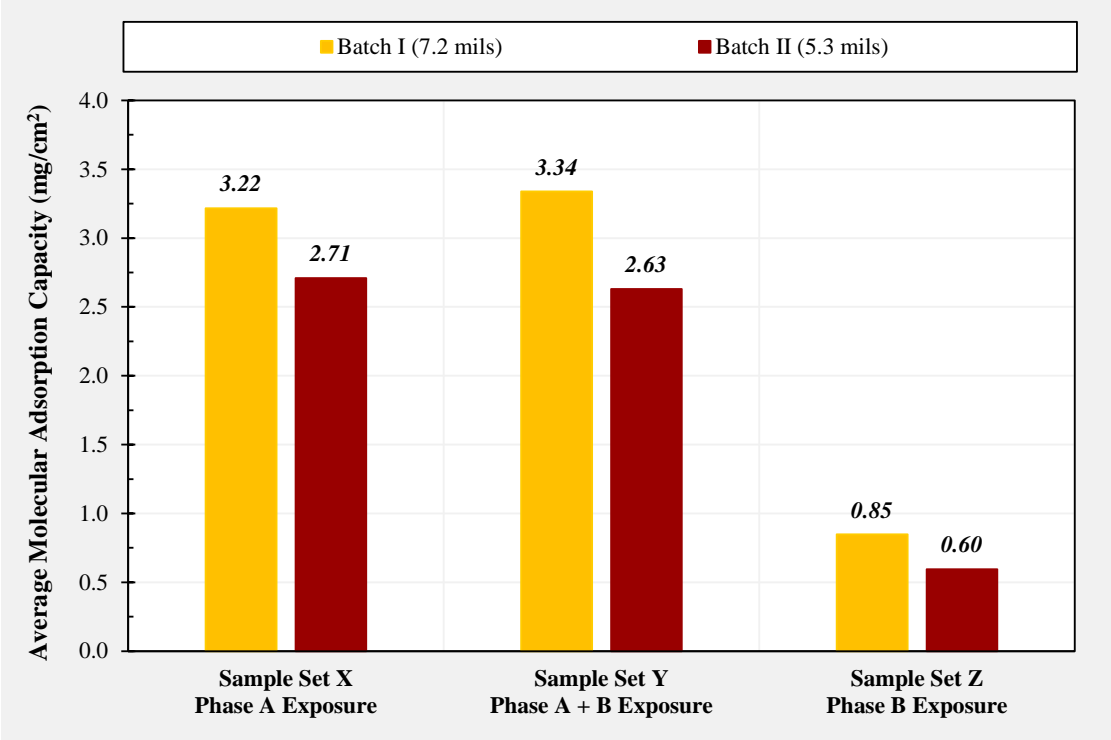

Figure 8. Average Gravimetric Molecular Adsorption Capacity per Sample Set and Phase Conditions

\subsection{Chemical Analysis Results}

\section{Comparison of Solvent Extraction Methods}

Figure 9 shows the amount of NVR collected from the eight samples that were analyzed using the two solvent extraction methods. Batch I with samples at 7.2 mils was used for the solvent rinse method. Batch II with samples at 5.3 mils was used for the solvent submerge method. In general, the solvent submerged samples resulted in a higher amount of NVR collection than the solvent rinsed samples. The control samples that were exposed only to ATLO simulated conditions had the least amount of NVR at 0.06 and $0.10 \mathrm{mg}$ for Method 1 and Method 2, respectively. For Method 1, the samples exposed to Phase A, Phase A+B, and Phase B resulted in 117, 114, and 6 times greater amounts of NVR than the control sample, respectively. Similarly, Phase A, Phase A+B, and Phase B samples for 
Method 2 resulted in 107, 98, and 3 times greater amounts of NVR than the control sample, respectively. Phase A appears to have the most adsorbed species, whereas Phase B has the least adsorbed of the contaminated samples. These trends are consistent with the results achieved from the gravimetrically derived molecular adsorption capacity values. ${ }^{23}$

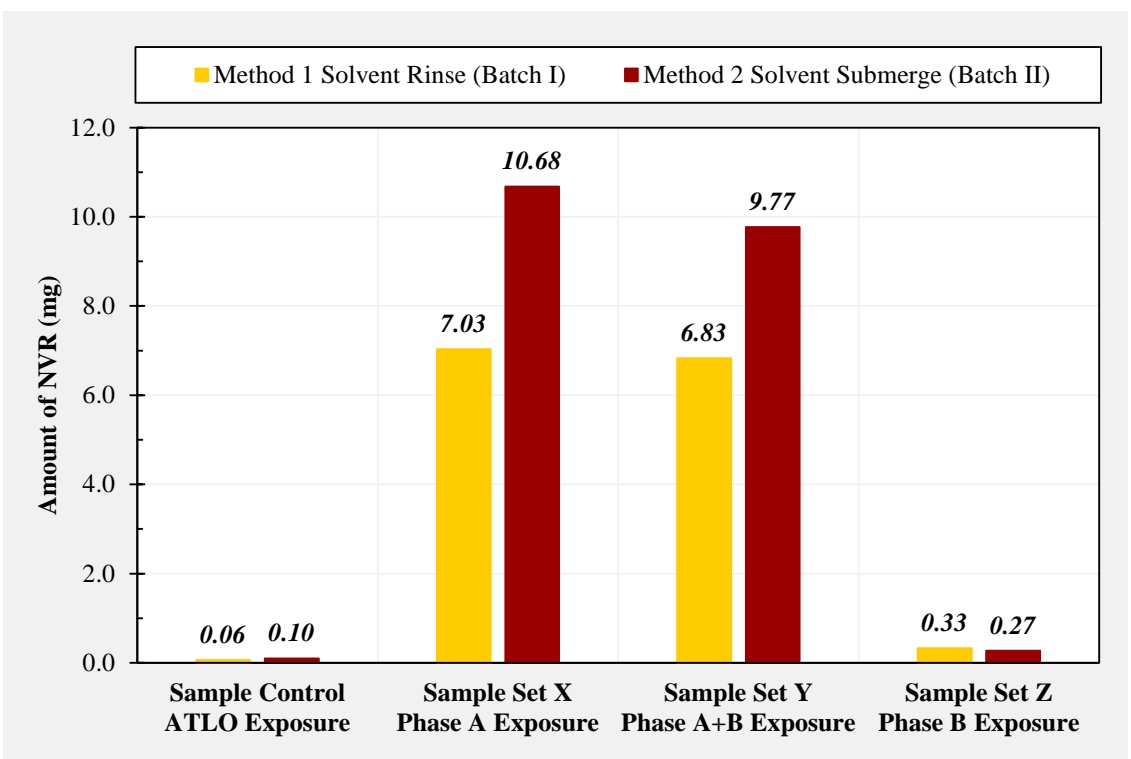

Figure 9. Amount of NVR from Solvent Extraction Methods and Sample Batches

\section{Comparison to Gravimetric Analysis}

As shown in Figure 10, three samples with similar gravimetric molecular adsorption capacity values from each batch were compared to the NVR mass per coating area results of the two solvent extraction methods. The first plot in Figure 10 illustrates the comparison of the adsorption per coating area with Method 1, in which the three selected samples from Batch I were rinsed with chloroform three times. Similarly, the second plot illustrates the results for Method 2, in which the remaining three samples from Batch II were submerged in chloroform. For all phases, the data suggest that the solvent submerge results were closer to the gravimetric molecular adsorption capacity values than Method 1. The difference between Method 1 and the gravimetric results ranged from 0.9 to $1.5 \mathrm{mg} / \mathrm{cm}^{2}$. In contrast, the difference in Method 2 and the gravimetric results was slightly less, ranging from 0.5 to $0.8 \mathrm{mg} / \mathrm{cm}^{2}$.
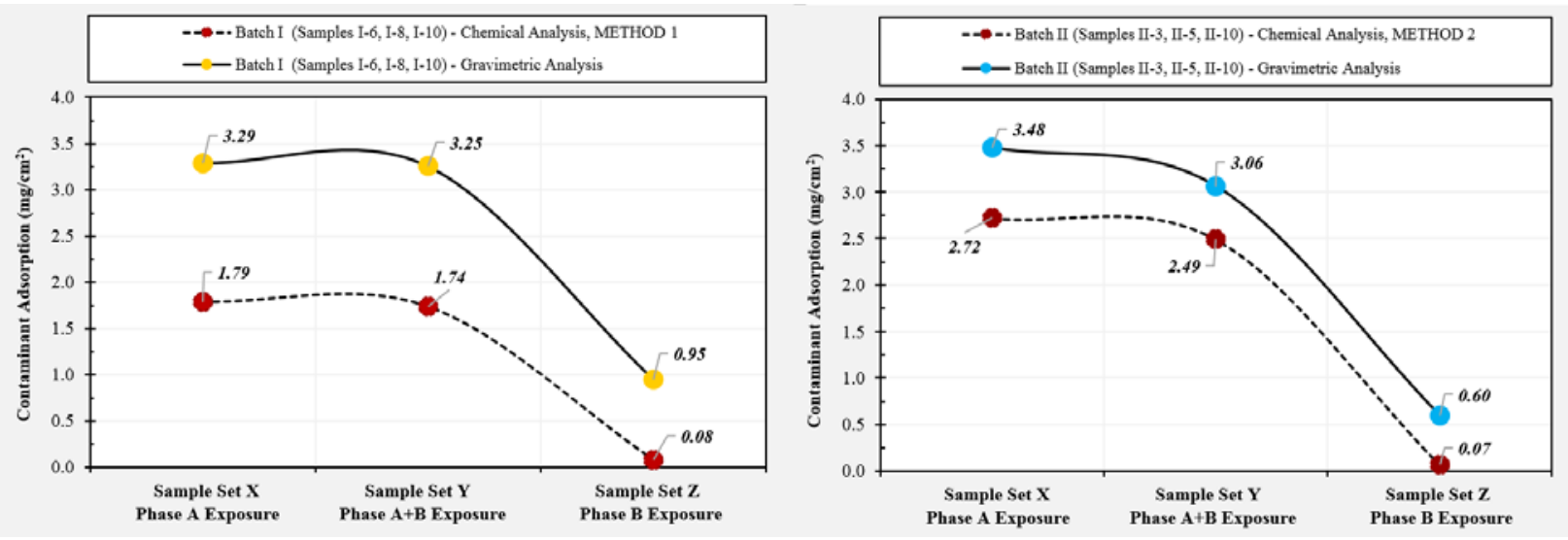

Figure 10. Comparison of Gravimetric and Chemical Analysis for Batch I and II 


\section{Pyrolysis-GC/MS}

The pyrolysis-GC/MS results for Method 1 and Method 2 are described in Table 7. The results for all six contaminated samples from any phase exposure, regardless of the method used, indicate that the majority of the NVR consisted of DOP. This is clearly exemplified in Figure 11, which shows the GC/MS plots for the samples that were analyzed using the solvent submerge method. The plots in Figure 11 illustrate that there were no other discernable peaks from the baseline noise for Samples II-3, II-5, and II-10. The relative intensity, or compound abundance, of DOP is the largest in the Phase B exposed sample. This is most likely attributed to the low amount of NVR compared to the samples from Sample Sets X and Y. ${ }^{23}$

Similar trends were also observed in the GC/MS plots for the four samples that were analyzed using the solvent rinse method. Figure 12 shows the similarities in the detection of the DOP peak in two Phase A exposed samples using the two solvent extraction methods. Lastly, the results of both methods for the two control samples, which were exposed to simulated ATLO conditions, confirm that no detectable organics were present. This is shown in Table 7 and demonstrated in the GC/MS plot for Sample II-14 in Figure 11. ${ }^{23}$

METHOD 1 Solvent Rinse

Sample Batch I (7.2 mils)

\begin{tabular}{|c|c|c|c|c|c|}
\hline Exposure & Sample Set & Sample & Chemical Species & Sample & Chemical Species \\
\hline ATLO & Control & I-14 & No detectable organics & II-14 & No detectable organics \\
\hline Phase A & X & I-6 & $\sim 100 \%$ DOP & II-3 & $\sim 100 \%$ DOP \\
\hline Phase A + B & Y & I-8 & $\sim 100 \%$ DOP & II-5 & $\sim 100 \%$ DOP \\
\hline Phase B & Z & I-10 & $\sim 100 \%$ DOP & II-10 & $\sim 100 \%$ DOP \\
\hline
\end{tabular}

Table 7. Summary of the Identified Chemical Species from Pyrolysis-GC/MS 

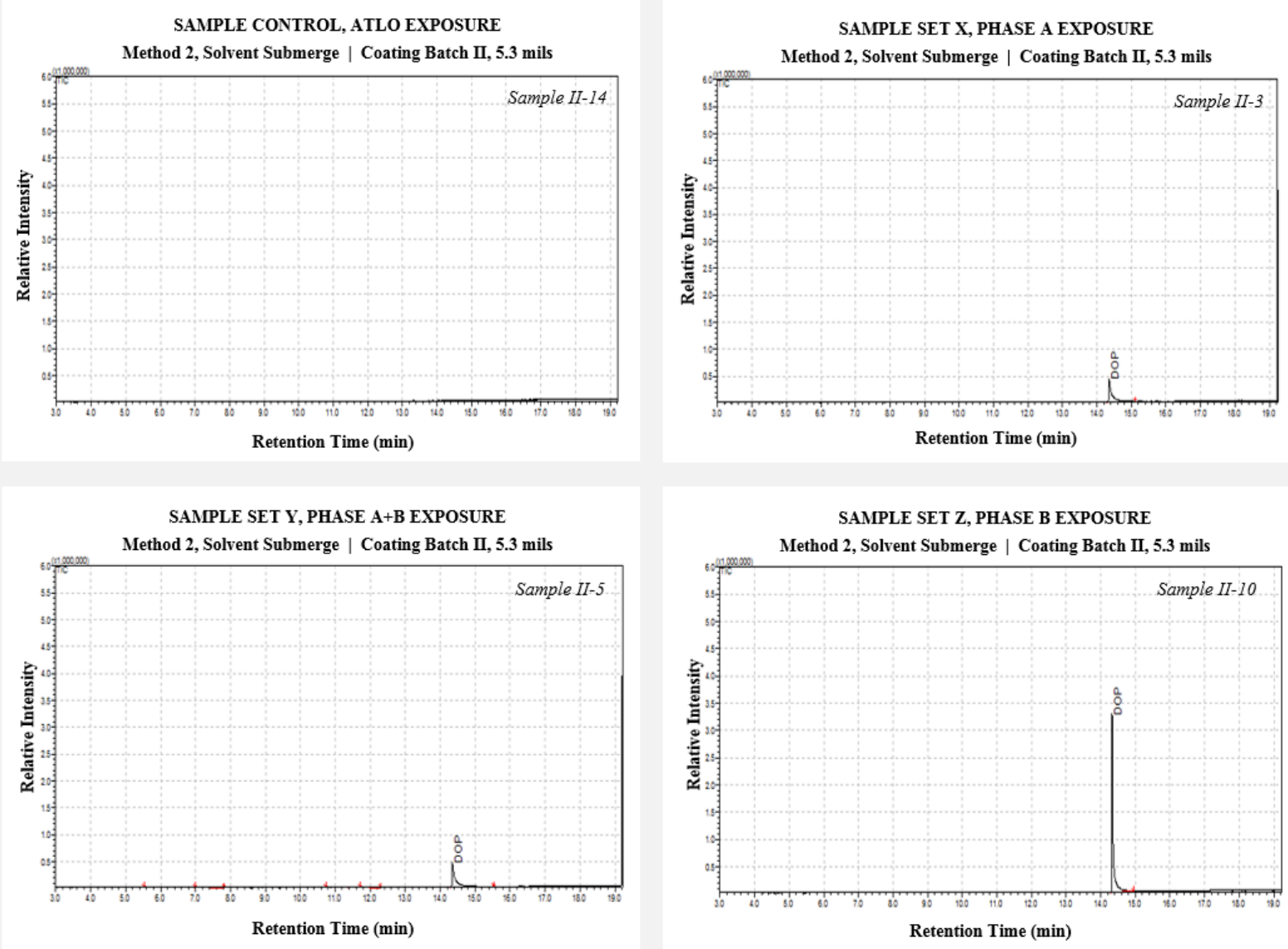

Figure 11. Comparison of Method 2 GC/MS Plots for Batch II Samples
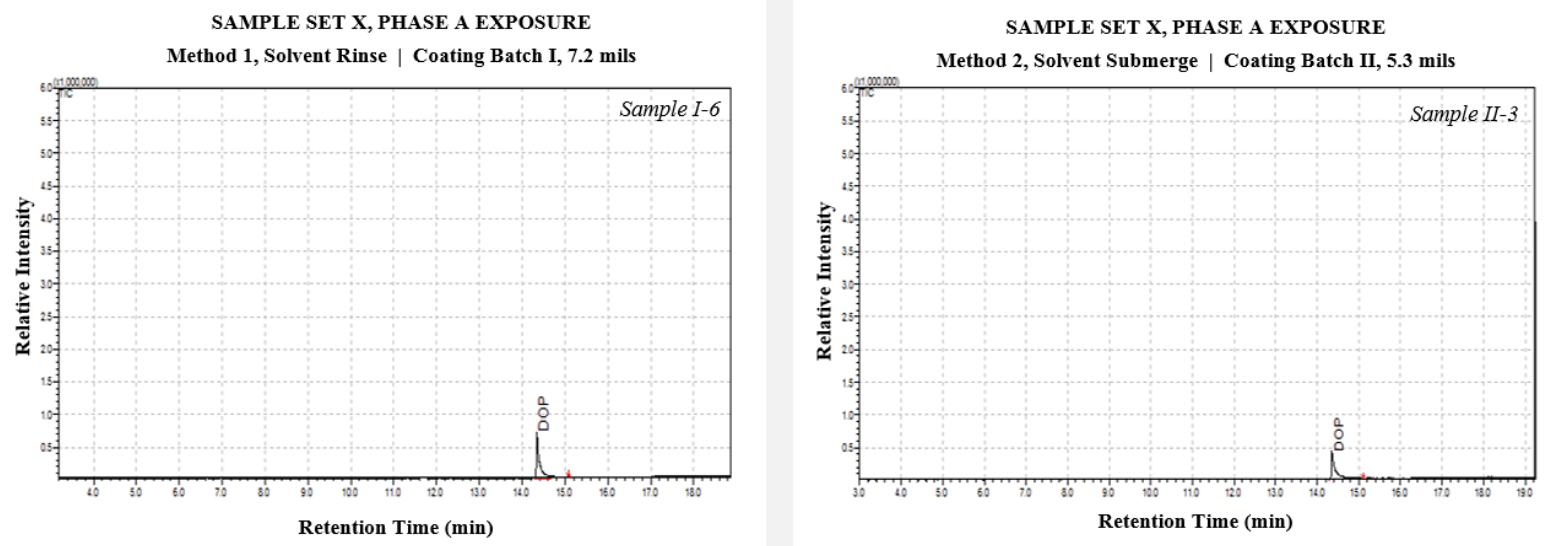

Figure 12. Comparison of Method 1 and Method 2 GC/MS Plots for Phase A Exposure Samples 


\section{CONCLUSIONS}

In conclusion, the preliminary test results confirm that NASA's MAC technology is effective at adsorbing high molecular weight plasticizers, such as DOP, in simulated spaceflight conditions that are representative of the vacuum environment of space and the Martian atmosphere. The results support the use of MAC for applications that require the reduction of harmful outgassed molecular species within critical hardware components, as well as, those that need to meet challenging molecular contamination requirements. Future work may include exploring other contaminants of interest, such as low molecular weight chemical species, performing additional tests in low vacuum carbon dioxide purged systems, as well as, tailoring the coating as needed for mission specific applications. 


\section{ACKNOWLEDGEMENTS}

The authors of this paper would like to acknowledge the NASA Mars 2020 program office for funding and supporting these test efforts. In particular, the authors acknowledge the following individuals who have contributed their time and provided their expertise for this project.

\begin{tabular}{|c|c|c|c|}
\hline Expertise Area & Team Member & $\begin{array}{c}\text { Company } \\
\text { Affiliation }\end{array}$ & $\begin{array}{c}\text { GSFC } \\
\text { Organization }\end{array}$ \\
\hline Contamination Control & Carlos Soares & JPL & - \\
\hline \multirow{2}{*}{$\begin{array}{c}\text { Vacuum Chamber } \\
\text { Test Operations }\end{array}$} & Kenneth O’Connor & SGT, Inc & Code 546 \\
& George Harris & SGT, Inc & Code 546 \\
& Griffin Jayne & SGT, Inc & Code 546 \\
\hline \multirow{2}{*}{ Thermal Coatings } & Alfred Wong & EDGE & Code 545 \\
\hline \multirow{2}{*}{ Chemical Analysis } & Mark Hasegawa & NASA GSFC & Code 546 \\
\hline Summer Intern & Jeremy Knipple & SGT, Inc & Code 541 \\
\hline
\end{tabular}

Table 8. Project Team Member Acknowledgements

\footnotetext{
JPL Jet Propulsion Laboratory

NASA National Aeronautics and Space Administration

GSFC Goddard Space Flight Center

SGT, Inc Stinger Ghaffarian Technologies, Incorporated

EDGE Edge Space Systems, Incorporated

Code 541 Materials Engineering Branch

Code 545 Thermal Engineering Branch

Code 546 Contamination and Coatings Engineering Branch
} 


\section{REFERENCES}

[1] National Aeronautics and Space Administration, "NASA Science Mars Exploration Program", Accessed 25 June 2018, <https://mars.nasa.gov/>

[2] National Aeronautics and Space Administration, “Journey to Mars: Overview”, Accessed 25 June 2018, $<$ https://www.nasa.gov/content/journey-to-marsoverview $>$

[3] National Aeronautics and Space Administration, "Red Planet”, Accessed 25 June 2018, $<$ https://mars.nasa.gov/\#red_planet/1>

[4] National Aeronautics and Space Administration, "All About Mars: Facts”, Accessed 25 June 2018, $<$ https://mars.nasa.gov/all-about-mars/facts/>

[5] Farley, K.A., Williford, K, et al., "Contamination Knowledge Strategy for the Mars 2020 Sample Collecting Rover", Lunar and Planetary Science Exploration Conference XLVIII (March 2017)

[6] Giuliani, M., Amerio, E., et al., "Contamination Control Approach for Exomars Mission”, 11 ${ }^{\text {th }}$ ISME International Symposium on Materials in a Space Environment (September 2009)

[7] Perry, R., Canham, J., and Lalime, E., "Developing the Cleanliness Requirements for an Organic Detection Instrument: Mars Organic Molecule Analyzer-Mass Spectrometer (MOMA-MS)", Contamination, Coatings, Materials and Planetary Protection Workshop, (July 2015)

[8] Abraham, N. S., Hasegawa, M. M., and Straka, S. A., "Development and testing of molecular adsorber coatings”, Proc. SPIE 8492, Optical System Contamination: Effects, Measurements, and Control 2012, 849203 (October 2012)

[9] Abraham, N. S., Hasegawa, M. M., and Straka, S. A., "Black molecular adsorber coatings for spaceflight applications”, Proc. SPIE 9196, Systems Contamination: Prediction, Measurement, and Control 2014, 91960F (September 2014)

[10] Abraham, N. S., "NASA Applications of Molecular Adsorber Coatings", Contamination, Coatings, Materials Science, and Planetary Protection Workshop (July 2015)

[11] Abraham, N. S., "NASA Applications of Molecular Adsorber Coatings", Thermal and Fluids Analysis Workshop (August 2015)

[12] Abraham, N. S., Hasegawa, M. M., and Secunda, M. S., "Application of the Molecular Adsorber Coating technology on the Ionospheric Connection Explorer program”, Proc. SPIE 9952, Systems Contamination: Prediction, Control, and Performance 2016, 99520D (September 2016)
[13] Abraham, N. S., Hasegawa, M. M., Wooldridge, E. M., and Henderson-Nelson, K. A., "The use of the Molecular Adsorber Coating technology to mitigate vacuum chamber contamination during Pathfinder testing for the James Webb Space Telescope”, Proc. SPIE 9952, Systems Contamination: Prediction, Control, and Performance 2016, 99520C (September 2016)

[14] Abraham, N. S., "Application of Molecular Adsorber Coatings in Chamber A for the James Webb Space Telescope”, Contamination, Coatings, Materials Science, and Planetary Protection Workshop (July 2017)

[15] National Aeronautics and Space Administration, “How long would a trip to Mars take?”, Published 10 Jan 2018, Accessed 25 June 2018, < https://image.gsfc.nasa.gov/poetry/venus/q2811.html>

[16] Williams, M., "Mars Compared to Earth", Universe Today, Accessed 25 June 2018, $<$ https://www.universetoday.com/22603/marscompared-to-earth/>

[17] National Aeronautics and Space Administration, "Mars Fact Sheet", Accessed 25 June 2018, $<$ https://nssdc.gsfc.nasa.gov/planetary/factsheet/marsf act.html $>$

[18] Sigma Aldrich, "Dioctyl phthalate”, Accessed 25 June 2018, <https://www.sigmaaldrich.com/catalog/ product/aldrich/d201154?lang=en\&region=US $>$

[19] National Institute of Standards and Technology, "Din-octyl phthalate", Pub Chem Open Chemistry Database, Accessed 25 June 2018, $<$ https://webbook.nist.gov/cgi/cbook.cgi?ID=C117840 \&Units=SI\&Mask=FFF\#ref-5>

[20] Perry, E.S., Weber, W.H., Vapor Pressures of Phlegmatic Liquids. II. High Molecular Weight Esters and Silicone Oils, J. Am. Chem. Soc., 1949, 71, 11, 3726-3730

[21] National Institutes of Health, "Bis(2ethylhexyl)phthalate”, Pub Chem Open Chemistry Database, Accessed 25 June 2018, < https://pubchem.ncbi.nlm.nih.gov/compound/8343>

[22] Chemistry LibreText ${ }^{\mathrm{TM}}$ Libraries, "ClausiusClapeyron Equation”, Accessed 25 June 2018, <https://chem.libretexts.org/Textbook_Maps/Physical _and_Theoretical_Chemistry_Textbook_Maps/Supple mental_Modules_(Physical_and_Theoretical_Chemist ry)/Physical_Properties_of_Matter/States_of_Matter/P hase_Transitions/Clausius-Clapeyron_Equation>

[23] Jallice, D., "Materials Engineering Report MEB \# 15422”, NASA GSFC Code 541 (December 2016) 